\title{
The Burden of Pain Associated with Osteoarthritis in the Hip or Knee from the Patient's Perspective: A Multinational Cross-Sectional Study
}

\author{
James Jackson (D) - Ravi Iyer · Jennifer Mellor $\cdot$ Wenhui Wei
}

Received: May 12, 2020 / Published online: July 29, 2020

(C) The Author(s) 2020
Work Productivity and Activity Impairment Questionnaire: Specific Health Problem. Bivariate testing compared outcomes using patients with no/mild pain without opioid use as the reference group.

Results: The study population comprised 2170 patients (US: $n=623$ [28.7\%]; EU: $n=1547$ [71.3\%]) with knee (54.9\%), hip (24.6\%), or knee/hip (20.5\%) OA. Mean (SD) age was 66.4 (11.2) years. Patients had no/mild pain without opioid use $(39.6 \%)$, no/mild pain with opioid use $(10.2 \%)$, moderate/severe pain without opioid use (30.6\%), and moderate/severe pain with opioid use (19.7\%). Compared with the reference group, patients with moderate/severe pain reported significantly $(p<0.05)$ higher functional limitations, greater use of $\geq 3$ treatments and treatment dissatisfaction, reduced quality of life, and impaired work productivity and activity. The burden was highest with moderate/severe pain with opioid use. Results were generally similar in the US and EU cohorts. Conclusions: The results from this multinational cross-sectional study indicate that the impact of OA pain is multidimensional, worsened by increasing pain intensity, and may not be adequately addressed by current treatment strategies.

Keywords: Comorbidity; Daily activity; Healthrelated quality of life; Opioid; Osteoarthritis; Pain; Physical functioning; Work productivity

W. Wei

Health Economics and Outcomes Research, Regeneron Pharmaceuticals, Inc., Tarrytown, NY, USA 


\section{Key Summary Points}

Why carry out this study?

Osteoarthritis (OA) is a chronic joint disease that represents a major global public health problem; pain is the main symptom of OA and the disease characteristic that most often drives patients to seek medical attention.

The objective of this cross-sectional study was to evaluate the burden of pain associated with knee, hip, or knee and hip OA from the perspective of adult patients in the USA and selected countries in the European Union (EU).

\section{What was learned from the study?}

Of 2170 patients with OA, those with moderate/severe pain reported significant burdens that affected multiple aspects of their lives.

The burdens were higher among patients with moderate/severe pain versus no/mild pain and among patients with current opioid use versus patients without current opioid use, regardless of pain intensity.

These results indicate that the multidimensional impact of OA pain is worsened by increasing pain intensity and may not be adequately addressed by opioid therapy, underscoring the need for alternative therapeutic agents for the management of knee/hip OA pain.

\section{INTRODUCTION}

Osteoarthritis (OA) is a chronic joint disease that represents a major global public health problem [1,2]. Affecting more than 300 million adults globally [2], $\mathrm{OA}$ is the most common form of arthritis and a leading cause of disability [1]. Although OA can involve any synovial joint
[1], the most commonly affected sites are the hips, knees, and hands [2]. Risk factors for OA include joint injury, increasing age, female sex, obesity, and predisposing genetic factors [3]. An aging population and increased rates of obesity are contributing to the growing incidence of $\mathrm{OA}$ [1]. OA can be defined in terms of radiologic changes as well as symptoms, although there may be a discordance between these findings, with some patients having radiologic findings without symptoms [4]. Pain is the disease characteristic that most often drives patients to seek medical attention [4], and it negatively affects multiple aspects of a patient's life, including mobility, sleep, mood, and healthrelated quality of life (HRQoL) [5]. OA is also associated with a substantial economic burden $[4,6]$. Although there is no cure for OA, a variety of therapies are available for OA pain, including non-pharmacologic approaches (e.g., physical therapy and weight management) and pharmacologic agents (e.g., acetaminophen [paracetamol], nonsteroidal anti-inflammatory drugs [NSAIDs], and opioids) [7].

Opioids have been traditionally recommended as options for OA pain $[8,9]$ and are still being prescribed in some patients [10]. However, use of opioids to manage OA pain remains controversial. Results from randomized controlled trials (RCTs) demonstrated that opioids provide few benefits relative to other analgesics for relieving OA pain [11-14]. Furthermore, opioids are associated with a number of safety concerns, including toxicities and the risk of abuse and dependency [15-17]. Conseqeuntly, the recently updated guidelines from the Osteoarthritis Research Society International (OARSI) strongly recommend against opioid use for OA pain [18]. In addition, the most recent guidelines from the American College of Rheumatology (ACR)/Arthritis Foundation (AF) conditionally recommend against the use of opioids in patients with OA, acknowledging that these agents may be used after exhausting other treatment options [19].

The objective of this multinational crosssectional study was to evaluate the burden of pain associated with OA in the hip and/or knee from the perspective of adult patients in the US 
and selected countries in the European Union (EU). In this study, patients with hip/knee OA were stratified based on pain intensity and the presence/absence of current opioid use. Given that OA exerts multiple effects on patients' lives, this study examined a spectrum of measures of disease burden, including functional burden, unmet treatment needs, comorbidity burden, HRQoL, work productivity, and daily activity.

\section{METHODS}

\section{Study Design}

This study utilized data from the Adelphi Disease Specific Programme (DSP) ${ }^{\mathrm{TM}}$, which is a large, multinational, observational study designed to capture a cross-section of real-world data for a range of common chronic diseases [20]. This study used de-identified, aggregated patient data and was granted exceptions from requiring ethics approval. Patients provided consent to participate. Data were collected in clinical practice settings by physicians who provided relevant information on consecutive patients consulting for the disease of interest. Patients were invited to participate by completing an independent questionnaire. Data were drawn from the 2017 global Adelphi OA DSP, which surveyed primary care physicians, rheumatologists, orthopedists, and their patients with OA during their regular office visits. Physician and patient data were collected at the same time. Participating physicians and patients were each assigned a study number to aid anonymous data collection and to allow linkage of data during data collection and analysis. This study included patients from the US and the five most populated EU countries at the time of the analysis (Germany, France, UK, Italy, and Spain [21]) who were diagnosed with OA of the knee and/or hip by their consulting physicians. For each included patient, during the visits physicians completed a patient record form on the patient's history of OA treatment regimens, current use of opioids and other treatments for $\mathrm{OA}$ pain, and comorbidities. Patients who agreed to participate completed a self-assessment form that included questions and validated measures for evaluating disease burden. OA pain intensity in the past $48 \mathrm{~h}$ was measured using the Western Ontario and McMaster Universities Osteoarthritis Index (WOMAC) Numerical Rating Scale (NRS) 3.1, a widely used, validated, self-administered, disease-specific questionnaire $[22,23]$. Using the pain component of the WOMAC, patients were stratified by no/mild pain (score 0-3) and moderate/severe pain (score 4-10) and at the same time by the presence or absence of current opioid use, resulting in four groups: no/mild pain without current opioid use; no/mild pain with current opioid use; moderate/severe pain without current opioid use; moderate/severe pain with current opioid use.

\section{Outcome Measures}

Outcomes included measures for physical functioning, unmet treatment needs, comorbidity, HRQoL, and work productivity and daily activity. Physical functioning was reported by patients using physical function and stiffness scores from the WOMAC NRS 3.1, which are scored on a range from 0 to 10 , with higher scores indicating a worse condition over the past $48 \mathrm{~h}$ $[22,23]$. Physical functioning was also assessed by patient responses to stand-alone questions related to functional limitations ("Has your mobility been impacted due to your OA?" "Do you need an aid to get around, either inside or outside of your house due to your OA?" "Do you need anyone to help you with any daily activities or tasks?" "Have you ever suffered a fall inside or outside of your home that you believe was because of your OA?"); these questions were not previously validated. Unmet treatment needs were measured by the use of $\geq 3$ treatment regimens for $\mathrm{OA}$ and patient-reported dissatisfaction with treatment. Comorbidity burden was evaluated by the physician using the Charlson Comorbidity Index (CCI) [24]. To further examine relevant comorbidities, rates of any cardiovascular condition, hypertension, depression or anxiety, osteoporosis, and chronic low back pain were recorded by the physician. 
HRQoL was measured using the 5-dimension, 5-level EuroQol (EQ-5D-5L), a generic, patient-reported measure of health status [25]. The EQ-5D-5L consists of five dimensions (mobility, self-care, usual activities, pain/discomfort, and anxiety/depression), with five levels of impairment responses, and a health state visual analog scale (VAS; $0=$ worst health state, $100=$ best health state). Patient responses on the five dimensions are used to generate a utility index that represents a health state with anchors at 0 (death) and 1 (perfect health), although index scores $<0$ are possible. For the EQ-5D-5L utility index, individual country value sets were used for the US and EU countries. The minimally important difference (MID) for the EQ-5D-5L utility index is estimated to be a difference of $>0.037$ to 0.069 points [26].

Work productivity and daily activity over the past 7 days were assessed using the patient-reported Work Productivity and Activity Impairment Questionnaire: Specific Health Problem (WPAI:SHP) version 2.0, with OA as the specified disease [27]. Activity impairment was assessed among all patients; work productivity was assessed among employed patients only. Assessed WPAI:SHP scales were impairment while working due to problem ("presenteeism"), work time missed ("absenteeism"), overall work impairment, and activity impairment.

\section{Statistical Analysis}

STATA v16.0 software was used in the statistical analysis. Bivariate testing was used to compare outcomes for patients with no/mild pain without current opioid use versus those with no/ mild pain with current opioid use, moderate/severe pain without current opioid use, and moderate/severe pain with current opioid use. Statistical significance was set at $p<0.05$.

\section{RESULTS}

\section{Patient Characteristics}

The study sample comprised 2170 patients with OA of the knee and/or hip from the 2017 global
Adelphi OA DSP (Table 1). The mean age was 66.4 years, $57.9 \%$ of patients were female, and $88.4 \%$ were white or Caucasian. OA was reported in the knee (without hip), hip (without knee), or both hip and knee in 54.9\%, 24.6\%, and $20.5 \%$ of patients, respectively (OA may have been present in joints other than the knee or hip). Participating patients were from the US $(n=623 ; 28.7 \%)$ and $\mathrm{EU}(n=1547 ; 71.3 \%)$.

Among the study sample, 1090 patients $(50.2 \%)$ had moderate/severe pain and 648 patients $(29.9 \%)$ were currently receiving opioids. Despite current opioid treatment, 427 of the 648 patients $(65.9 \%)$ still reported moderate/severe pain. Based on pain severity and opioid use, patients were grouped into four categories: 859 patients $(39.6 \%)$ had no/mild pain without opioid use, 221 patients $(10.2 \%)$ had no/mild pain with opioid use, 663 patients (30.6\%) had moderate/severe pain without opioid use, and 427 patients (19.7\%) had moderate/severe pain with opioid use (Supplementary Fig. 1).

Demographic and clinical characteristics were generally consistent across the four categories, although patients with moderate/severe pain with opioid use were older, had a higher proportion of females, had a higher incidence of OA affecting both the knee and hip, and had a higher incidence of obesity (Table 1 ). Moderate/severe pain was reported by 248 of 623 US patients (39.8\%) and 842 of 1547 EU patients $(54.4 \%)$, and opioids were used by 141 US patients (22.6\%) and $507 \mathrm{EU}$ patients (32.8\%; Supplementary Fig. 1). Opioids were used by $46.1 \%$ of patients in Spain, 39.8\% of patients in the UK, $29.7 \%$ of patients in Italy, $27.4 \%$ of patients in Germany, and $25.5 \%$ of patients in France (Supplementary Fig. 2). Despite receiving opioids, 93 patients (14.9\%) in the US cohort and 334 patients $(21.6 \%)$ in the EU cohort still reported moderate/severe pain (Supplementary Fig. 1). The proportion of patients with moderate/severe pain and opioid use was 33.3\% in Spain, $25.7 \%$ in the UK, $23.9 \%$ in Italy, $16.7 \%$ in France, and $15.0 \%$ in Germany (Supplementary Fig. 2).

Among current opioid users $(n=648)$ in the total population, 463 patients $(71.5 \%)$ used weak opioids (e.g., codeine, hydrocodone, or 
Table 1 Characteristics of patients with hip and/or knee OA in the total population (US and EU cohorts; $N=2170$ ) by pain intensity and opioid use

\begin{tabular}{|c|c|c|c|c|c|}
\hline & $\begin{array}{l}\text { Total } \\
(N=2170)\end{array}$ & $\begin{array}{l}\text { No/mild pain } \\
\text { without opioid } \\
\text { use }(n=859)\end{array}$ & $\begin{array}{l}\text { No/mild pain } \\
\text { with opioid } \\
\text { use }(n=221)\end{array}$ & $\begin{array}{l}\text { Moderate/severe } \\
\text { pain without opioid } \\
\text { use }(n=663)\end{array}$ & $\begin{array}{l}\text { Moderate/severe } \\
\text { pain with opioid } \\
\text { use }(n=427)\end{array}$ \\
\hline \multicolumn{6}{|l|}{ Age } \\
\hline No & 2170 & 859 & $221^{\mathrm{c}}$ & $663^{\mathrm{c}}$ & $427^{\mathrm{c}}$ \\
\hline Mean $(\mathrm{SD}),{ }^{a}$ years & $66.4(11.2)$ & $64.5(10.9)$ & $68.0(9.7)$ & $66.2(11.6)$ & $69.8(10.8)$ \\
\hline \multicolumn{6}{|l|}{ Sex } \\
\hline No & 2170 & 859 & 221 & $663^{\mathrm{c}}$ & $427^{\mathrm{c}}$ \\
\hline Male & $914(42.1)$ & $389(45.3)$ & $101(45.7)$ & $266(40.1)$ & $158(37.0)$ \\
\hline Female & $1256(57.9)$ & $470(54.7)$ & $120(54.3)$ & $397(59.9)$ & $269(63.0)$ \\
\hline \multicolumn{6}{|l|}{ Race/ethnicity } \\
\hline No & 2170 & 859 & 221 & $663^{\mathrm{c}}$ & $427^{\mathrm{c}}$ \\
\hline White/Caucasian & 1919 (88.4) & $747(87.0)$ & $204(92.3)$ & $604(91.1)$ & $364(85.2)$ \\
\hline Hispanic/Latino & $88(4.1)$ & $31(3.6)$ & $6(2.7)$ & $22(3.3)$ & $29(6.8)$ \\
\hline African American & $72(3.3)$ & $41(4.8)$ & $6(2.7)$ & $13(2.0)$ & $12(2.8)$ \\
\hline Others & $91(4.2)$ & $40(4.7)$ & $5(2.3)$ & $24(3.6)$ & $22(5.2)$ \\
\hline \multicolumn{6}{|l|}{ Country } \\
\hline No & 2170 & 859 & $221^{\mathrm{c}}$ & $663^{c}$ & $427^{\mathrm{c}}$ \\
\hline US & $623(28.7)$ & $327(38.1)$ & $48(21.7)$ & $155(23.4)$ & $93(21.8)$ \\
\hline Germany & $468(21.6)$ & $178(20.7)$ & $58(26.2)$ & $162(24.4)$ & $70(16.4)$ \\
\hline France & $377(17.4)$ & $153(17.8)$ & $33(14.9)$ & $128(19.3)$ & $63(14.8)$ \\
\hline Spain & $306(14.1)$ & $77(9.0)$ & $39(17.6)$ & $88(13.3)$ & $102(23.9)$ \\
\hline UK & $241(11.1)$ & $78(9.1)$ & $34(15.4)$ & $67(10.1)$ & $62(14.5)$ \\
\hline Italy & $155(7.1)$ & $46(5.4)$ & $9(4.1)$ & $63(9.5)$ & $37(8.7)$ \\
\hline \multicolumn{6}{|l|}{ Site of $\mathrm{OA}^{\mathrm{b}}$} \\
\hline No & 2170 & 859 & $221^{\mathrm{c}}$ & 663 & $427^{\mathrm{c}}$ \\
\hline Knee (without hip) & $1192(54.9)$ & $516(60.1)$ & $102(46.2)$ & $371(56.0)$ & $203(47.5)$ \\
\hline Hip (without knee) & $533(24.6)$ & $183(21.3)$ & $73(33.0)$ & $167(25.2)$ & $110(25.8)$ \\
\hline Both knee and hip & $445(20.5)$ & $160(18.6)$ & $46(20.8)$ & $125(18.9)$ & $114(26.7)$ \\
\hline \multicolumn{6}{|l|}{ BMI } \\
\hline No & 2169 & 859 & 221 & 662 & $427^{\mathrm{c}}$ \\
\hline Mean (SD), $\mathrm{kg} / \mathrm{m}^{2}$ & $28.1(5.2)$ & $27.7(4.8)$ & $28.0(4.9)$ & $28.0(5.2)$ & $29.2(5.7)$ \\
\hline Obese & $641(29.6)$ & $221(25.7)$ & $65(29.4)$ & $189(28.5)$ & $166(38.9)$ \\
\hline$\left(\mathrm{BMI}>30 \mathrm{~kg} / \mathrm{m}^{2}\right)$ & & & & & \\
\hline
\end{tabular}


Table 1 continued

\begin{tabular}{|c|c|c|c|c|}
\hline tal & $\begin{array}{l}\text { No/mild pain } \\
\text { without opioid } \\
\text { use }(n=859)\end{array}$ & $\begin{array}{l}\text { No/mild pain } \\
\text { with opioid } \\
\text { use }(n=221)\end{array}$ & $\begin{array}{l}\text { Moderate/severe } \\
\text { pain without opioid } \\
\text { use }(n=663)\end{array}$ & $\begin{array}{l}\text { Moderate/severe } \\
\text { pain with opioic } \\
\text { use }(n=427)\end{array}$ \\
\hline
\end{tabular}

Employment status

\begin{tabular}{llllll} 
No & 2150 & 849 & $217^{\mathrm{c}}$ & $658^{\mathrm{c}}$ & $426^{\mathrm{c}}$ \\
Working full-time & $545(25.3)$ & $286(33.7)$ & $46(21.2)$ & $157(23.9)$ & $56(13.1)$ \\
Working part-time & $124(5.8)$ & $54(6.4)$ & $6(2.8)$ & $43(6.5)$ & $21(4.9)$ \\
On long-term sick leave & $17(0.8)$ & $2(0.2)$ & 0 & $5(0.8)$ & $10(2.3)$ \\
Homemaker & $256(11.9)$ & $93(11.0)$ & $26(12.0)$ & $72(10.9)$ & $65(15.3)$ \\
Student & $2(0.1)$ & 0 & 0 & $2(0.3)$ & 0 \\
Retired & $1156(53.8)$ & $406(47.8)$ & $136(62.7)$ & $364(55.3)$ & $250(58.7)$ \\
Unemployed & $50(2.3)$ & $8(0.9)$ & $3(1.4)$ & $15(2.3)$ & $24(5.6)$ \\
\hline
\end{tabular}

Values are the number (\%), unless indicated otherwise

$B M I$ body mass index, $E U$ European Union, $O A$ osteoarthritis, $S D$ standard deviation

a Patients aged $>90$ years were coded as being 90 years of age

b OA may have been present in joints other than the knee or hip

c $p<0.05$ compared with patients with no/mild pain without opioid use

tramadol), 171 patients (26.4\%) used strong opioids (e.g., morphine, hydromorphone, or oxycodone), and 14 patients (2.2\%) used weak and strong opioids in combination (Supplementary Fig. 3). In the total population, strong opioids were used more frequently in patients with moderate/severe pain than in those with no/mild pain $(29.0 \%$ versus $21.3 \%)$. Strong opioids were used most frequently in Germany $(53.9 \%)$, followed by Italy $(39.1 \%)$, Spain (32.6\%), the US (13.5\%), France $(11.5 \%)$, and the UK (8.3\%) (Supplementary Fig. 4).

\section{Physical Functioning}

In the total population, patients with moderate/severe pain reported higher scores in WOMAC physical function and stiffness than patients with no/mild pain, which was indicative of higher functional impairment (Fig. 1). In addition, patients with opioid use reported more physical function limitations than those without opioid use at the same pain level (i.e., patients with no/mild pain with opioid use had more limitations than those with no/mild pain without opioid use, as did patients with moderate/severe pain with opioid use versus those without opioid use; Fig. 1a). Patients with moderate/severe pain with opioid use experienced the most limitations in physical function and joint stiffness. WOMAC physical function and stiffness scores were more than twofold higher among patients with moderate/severe pain with or without opioid use compared with those with no/mild pain without opioid use $(6.3$ and 5.7 versus $2.5[p<0.05]$ and 6.3 and 5.7 versus $2.7[p<0.05]$, respectively). Patterns were similar in the US and EU cohorts (Fig. 1).

Higher rates of mobility limitation, need for a walking aid, need for help with daily activities, and suffering a fall were noted with moderate/severe pain than with no/mild pain (Table 2). Similarly, the prevalence of these limitations was higher among those with opioid 


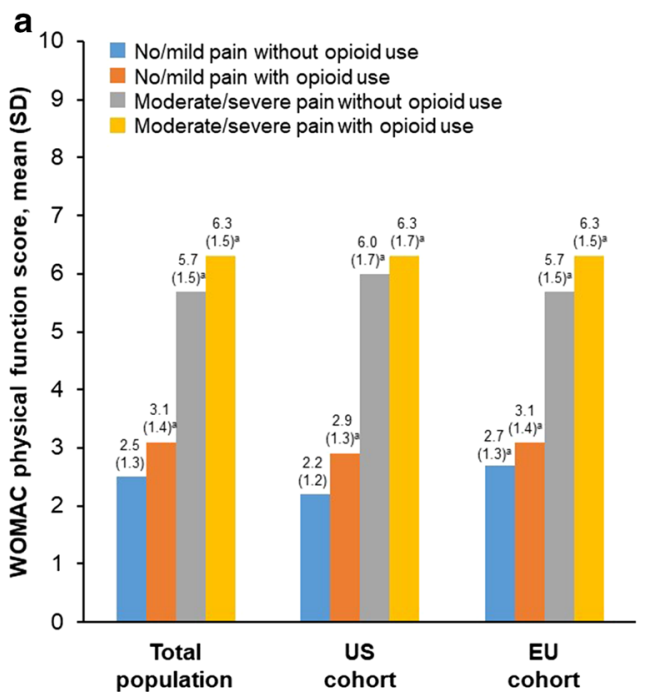

Fig. 1 WOMAC scores in patients with hip and/or knee $\mathrm{OA}$ by pain intensity and opioid use. a Physical function scores. b Stiffness scores. Scale ranges from 0 to 10 , with higher scores indicating worse condition. ${ }^{\mathrm{a}} p<0.05$ versus

use relative to those without opioid use at the same pain level (Table 2). These burdens were highest in patients with moderate/severe pain with opioid use and when compared with those with no/mild pain without opioid use showed more than a twofold higher need of a walking aid $(67.3 \%$ versus $30.0 \% ; p<0.05)$, almost a fivefold higher need for help with daily activities (48.9\% versus $10.2 \% ; p<0.05)$, and more than a twofold higher fall rate $(45.3 \%$ versus $17.6 \% ; p<0.05)$. Patterns for functional burdens were similar in the US and EU cohorts (Supplementary Tables 1 and 2).

\section{Treatment Needs}

Treatment needs (i.e., the requirement for three or more treatment regimens for OA pain or dissatisfaction with treatment) were higher with moderate/severe pain than with no/mild pain and with opioid use than with no opioid use at the same pain level (Table 2). Patients with moderate/severe pain with opioid use reported the greatest treatment needs. Among patients with moderate/severe pain with opioid use in the total population, approximately half $(50.1 \%)$ reported using three or more treatment

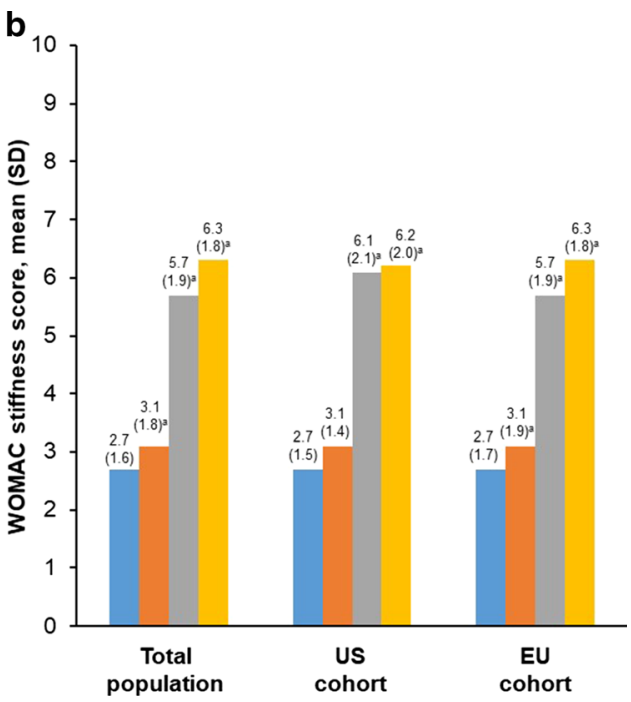

no/mild pain without opioid use. $E U$ European Union, $O A$ osteoarthritis, $S D$ standard deviation, WOMAC Western Ontario and McMaster Universities Osteoarthritis Index

regimens for OA pain and more than one-third (38.1\%) reported being dissatisfied with their treatment. Patterns in treatment needs were similar across the US and EU cohorts (Supplementary Tables 1 and 2).

\section{Comorbidity}

In the total population, the mean CCI score was approximately twofold higher among patients with current opioid use than those without opioid use at the same severity level (Fig. 2). Patients with moderate/severe pain with opioid use had the highest mean CCI score, which was significantly higher than those with no/mild pain without opioid use (0.74 versus 0.30 , respectively; $p<0.05$; Fig. 2). These trends were also observed in the US and EU cohorts.

Relevant comorbid conditions were more prevalent among patients with moderate/severe pain than among those with no/mild pain, as well as among patients with opioid use than among those with no opioid use at the same pain level (Table 2). Patients with moderate/severe pain with opioid use had the highest rates of comorbid conditions. Rates of depression or anxiety, osteoporosis, and chronic low 
Table 2 Burdens in patients with hip and/or knee OA in the total population (US and EU cohorts; $N=2170$ ) by pain intensity and opioid use

\begin{tabular}{|c|c|c|c|c|}
\hline & $\begin{array}{l}\text { No/mild pain } \\
\text { without opioid use } \\
(n=859)\end{array}$ & $\begin{array}{l}\text { No/mild pain } \\
\text { with opioid use } \\
(n=221)\end{array}$ & $\begin{array}{l}\text { Moderate/severe pain } \\
\text { without opioid use } \\
(n=663)\end{array}$ & $\begin{array}{l}\text { Moderate/severe pain } \\
\text { with opioid use } \\
(n=427)\end{array}$ \\
\hline \multicolumn{5}{|l|}{ Physical function } \\
\hline $\begin{array}{l}\text { Mobility limitation } \\
(n=2094)\end{array}$ & $432(52.4)$ & $149(69.0)^{c}$ & $498(78.2)^{\mathrm{c}}$ & $362(87.0)^{c}$ \\
\hline $\begin{array}{l}\text { Need for walking aid } \\
(n=1427)\end{array}$ & $129(30.0)$ & $67(45.3)^{c}$ & $225(46.1)^{c}$ & $243(67.3)^{c}$ \\
\hline $\begin{array}{l}\text { Need for help with } \\
\text { daily activities } \\
(n=2059)\end{array}$ & $83(10.2)$ & $46(21.4)^{c}$ & $183(29.3)^{c}$ & $197(48.9)^{\mathrm{c}}$ \\
\hline $\begin{array}{l}\text { Suffered a fall } \\
(n=2115)\end{array}$ & $148(17.6)$ & $47(21.7)$ & $195(30.6)^{c}$ & $189(45.3)^{c}$ \\
\hline \multicolumn{5}{|l|}{ Treatment needs } \\
\hline $\begin{array}{l}\text { Use of } \geq 3 \text { treatment } \\
\text { regimens for OA } \\
(n=1965)\end{array}$ & $102(13.9)$ & $90(40.7)^{\mathrm{c}}$ & $132(22.7)^{\mathrm{c}}$ & $214(50.1)^{c}$ \\
\hline $\begin{array}{l}\text { Dissatisfaction with } \\
\text { treatment }^{\mathrm{b}} \\
(n=1859)\end{array}$ & $40(5.8)$ & $22(10.6)^{c}$ & $144(25.5)^{c}$ & $153(38.1)^{\mathrm{c}}$ \\
\hline \multicolumn{5}{|l|}{ Comorbidity $(N=2170)$} \\
\hline $\begin{array}{l}\text { Any cardiovascular } \\
\text { condition }\end{array}$ & $421(49.0)$ & $151(68.3)^{c}$ & $379(57.2)^{c}$ & $308(72.1)^{\mathrm{c}}$ \\
\hline Hypertension & $388(45.2)$ & $142(64.3)^{c}$ & $355(53.5)^{c}$ & $283(66.3)^{c}$ \\
\hline Depression or anxiety & $129(15.0)$ & $49(22.2)^{c}$ & $146(22.0)^{\mathrm{c}}$ & $147(34.4)^{\mathrm{c}}$ \\
\hline Osteoporosis & $51(5.9)$ & $22(10.0)^{c}$ & $67(10.1)^{c}$ & $65(15.2)^{c}$ \\
\hline Chronic low back pain & $52(6.1)$ & $25(11.3)^{\mathrm{c}}$ & $85(12.8)^{c}$ & $93(21.8)^{\mathrm{c}}$ \\
\hline
\end{tabular}

Values are the number (\%)

$E U$ European Union, $O A$ osteoarthritis

${ }^{a}$ Among those who reported mobility limitation

b Among those currently treated

${ }^{c} p<0.05$ versus no/mild pain and no opioid use

back pain were more than twofold higher among patients with moderate/severe pain with opioid use compared with those with no/mild pain without opioid use $(p<0.05)$. The majority of patients with moderate/severe pain with opioid use had been diagnosed with any cardiovascular condition $(72.1 \%)$ or hypertension $(66.3 \%)$; more than one-third of these patients (34.4\%) suffered from anxiety or depression. Rates of comorbidities were slightly higher in the US than in the EU cohort, 


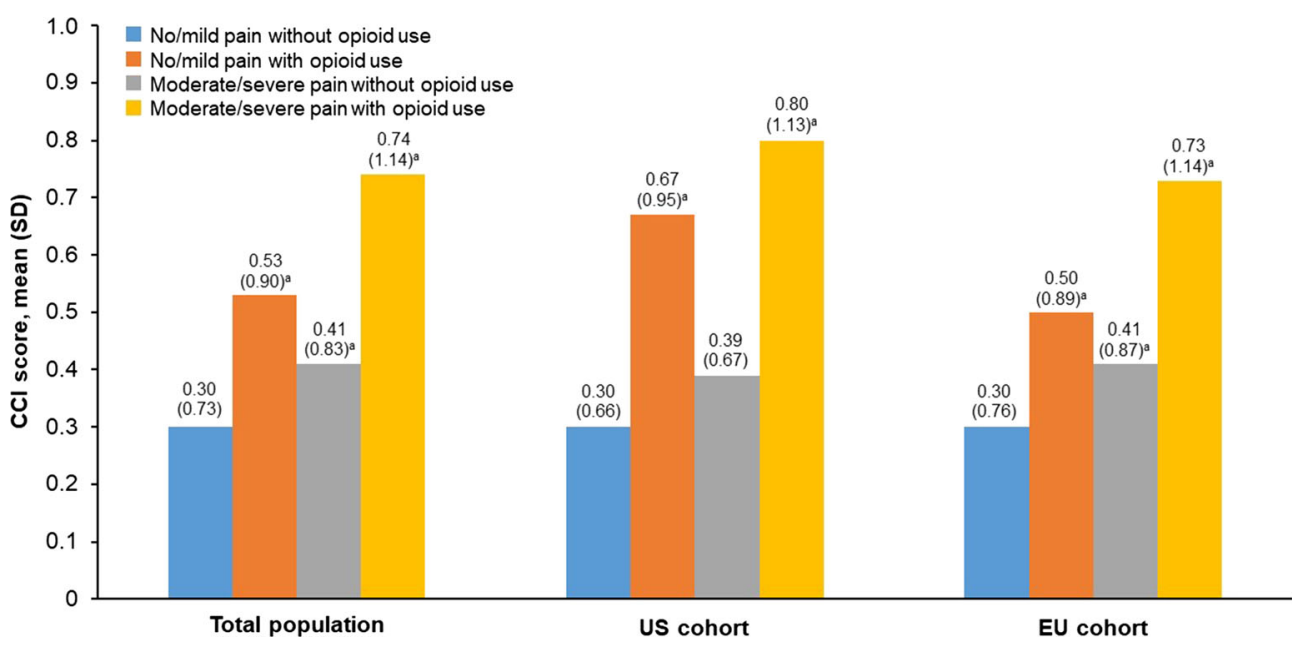

Fig. 2 CCI scores in patients with hip and/or knee OA by pain intensity and opioid use. ${ }^{a} p<0.05$ versus no/mild pain without opioid use. $C C I$ Charlson Comorbidity Index, EU European Union, $O A$ osteoarthritis, $S D$ standard deviation

although trends were similar between the two cohorts (Supplementary Tables 1 and 2).

\section{HRQoL}

HRQoL, as assessed by the EQ-5D-5L VAS and index scores, was lower among patients with moderate/severe pain than among those with no/mild pain as well as among those with opioid use than among those with no opioid use at the same pain level (Fig. 3). Differences in EQ5D-5L index scores between patients with no/ mild pain without opioid use and patients in the other three study groups were clinically relevant (i.e., exceeding the estimated MID of 0.037 [25]). Patients with moderate/severe pain with opioid use reported the poorest HRQoL. Mean EQ-5D-5L VAS and index scores were significantly lower among patients with moderate/severe pain with or without opioid use than among those with no/mild pain without opioids $(p<0.05)$. EQ-5D-5L VAS and utility index scores were slightly lower in the EU cohort than in the US cohort, although overall trends were similar.

\section{Work Productivity and Daily Activity}

In the total population, patients with moderate/severe pain reported greater percentages of work time missed due to problem (absenteeism; Fig. 4a), impairment while working due to problem (presenteeism; Fig. 4b), overall work impairment (Fig. 4c), and activity impairment (Fig. 4d) than patients with no/mild pain, as assessed by the WPAI:SHP. In addition, patients with opioid use generally reported greater percentage impairment on all WPAI:SHP scales than those without opioid use, regardless of pain level. The percentage of impairment due to presenteeism (Fig. 4b) exceeded that of absenteeism (Fig. 4a), regardless of pain level or opioid use.

In the total population, the greatest percentage impairment in WPAI:SHP scales was reported by patients with moderate/severe pain with opioid use. Patients with moderate/severe pain with or without opioid use, compared with those with no/mild pain without opioid use, reported significantly greater work productivity and daily activity impairment ( $p<0.05$; Fig. 4$)$. Across WPAI:SHP scales, reported impairment was more than twofold higher in patients with moderate/severe pain with opioid use compared with those with no/mild pain without opioid use. WPAI:SHP results were generally consistent across US and EU cohorts. However, among patients with moderate/severe pain with opioid use, the percentage of overall work impairment was substantially greater in the EU cohort than in the US cohort (60.9\% versus $41.8 \%$; Fig. $4 \mathrm{c})$, 


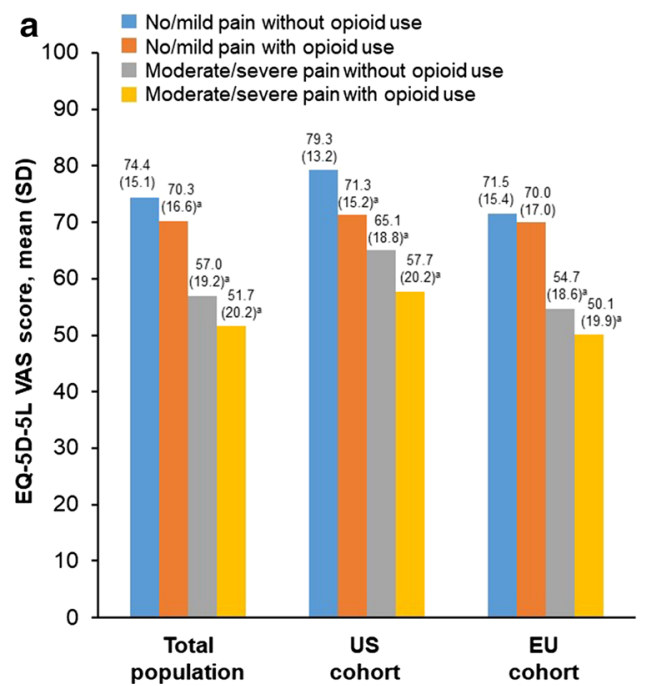

Fig. 3 EQ-5D-5L scores in patients with hip and/or knee $\mathrm{OA}$ by pain intensity and opioid use. a VAS scores. b Utility index scores. Higher scores indicate better quality of life. ${ }^{a} p<0.05$ versus no/mild pain without opioid use.

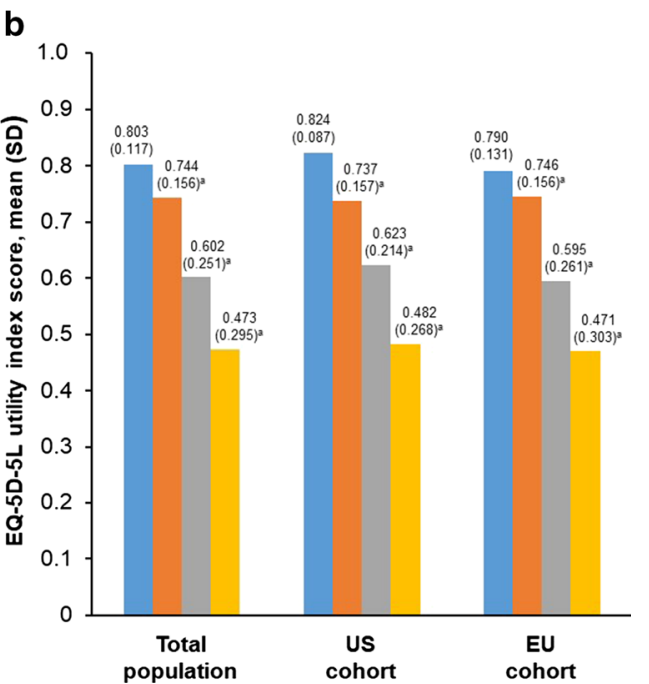

$E Q-5 D-5 L$ 5-dimension 5-level EuroQol, $E U$ European Union, $O A$ osteoarthritis, $S D$ standard deviation, $V A S$ visual analog scale
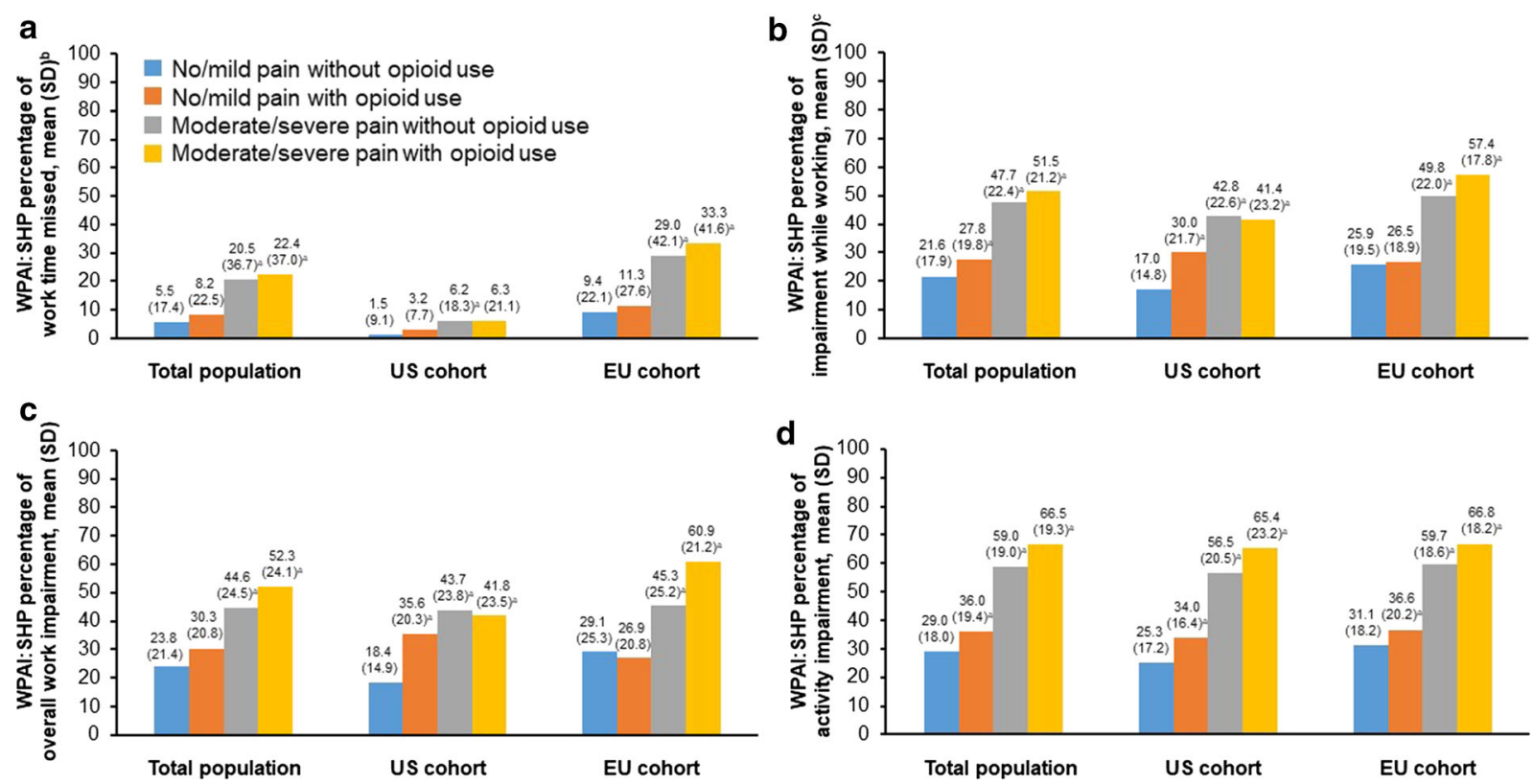

Fig. 4 WPAI:SHP scores in patients with hip and/or knee OA by pain intensity and opioid use. a Percentage of work time missed. b Percentage of impairment while working. c Percentage of overall work impairment. d Percentage of activity impairment. Activity impairment was assessed among all patients; work productivity was assessed among

employed patients only. ${ }^{a} p<0.05$ versus no/mild pain without opioid use. ${ }^{\mathrm{b}}$ Absenteeism. ${ }^{\mathrm{c}}$ Presenteeism. $E U$ European Union, $O A$ osteoarthritis, $S D$ standard deviation, WPAI:SHP Work Productivity and Activity Impairment Questionnaire: Specific Health Problem 
and absenteeism was more evident in the EU cohort than in the US cohort (Fig. 4a).

\section{DISCUSSION}

In this cross-sectional study, patients from the US and five EU countries with moderate/severe OA pain, regardless of opioid use, reported significant burdens that encompassed reductions in physical functioning, greater treatment needs, more comorbidities, reduced HRQoL, and impairments in work productivity and daily activities. The burdens were also generally higher among patients with current opioid use compared with those without current opioid use, regardless of pain intensity; patterns were generally similar across US and EU cohorts. Among the total study population, approximately half of patients with OA had moderate/severe pain, almost a third were currently receiving opioids, and approximately one-fifth still reported moderate/severe pain despite current opioid use.

$\mathrm{OA}$ is associated with a significant functional burden that can result in disability [4,5]; not surprisingly, the results from this study demonstrated greater functional impacts with higher pain intensity. Patients with moderate/severe pain were more likely than patients with no/mild pain to report impairment in physical function and stiffness, specific needs such as for a walking aid or help with daily activities, and that they suffered a fall. These results are consistent with evidence showing that pain is a major contributing factor to the functional limitations associated with OA [4].

The results from this study also demonstrated greater functional impacts among patients with OA pain using opioids. Patients using opioids reported more physical functional limitations than those not using opioids at the same pain level. These results suggest that opioids provided no benefit in some patients and may have even contributed to worse functional outcomes. The increased frequency of physical functional limitations, use of a walking aid, and falls with opioid use may potentially be related to opioid-related adverse events, specifically dizziness and somnolence. The results of this study also revealed greater unmet treatment needs among patients treated with opioids. In particular, more than half of patients with moderate/severe pain with opioid use reported using three or more treatment regimens for OA, possibly indicating the lack of efficacy with one or two regimens. Additionally, more than onethird of these patients reported treatment dissatisfaction, suggesting that management with opioids may not adequately address OA pain. Treatment dissatisfaction with opioids may be related to the toxicity and low efficacy in OA that are well-recognized issues associated with this drug class. These results are consistent with those from RCTs showing that opioids provide limited benefit to patients with OA pain [11-14] and support the recently updated OARSI and $\mathrm{ACR} / \mathrm{AF}$ guidelines, which strongly recommend against the use of opioids for managing OA pain $[18,19]$.

The results of this study confirm previous work showing high comorbidity among patients with OA [28-31] and further revealed that patients with higher pain intensity with current opioid use have the greatest level of comorbidity. Mean CCI scores were approximately two-fold higher with opioid use relative to no opioid use at the same severity level. Moreover, rates of depression or anxiety, osteoporosis, and chronic low back pain were more than twofold higher among patients with moderate/severe pain with current opioid use compared with those with no/mild pain without current opioid use. The majority of patients with moderate/severe pain with or without opioid use reported suffering from a cardiovascular condition or hypertension. Comorbidities are clinically relevant because they may predispose patients to the adverse effects of analgesics (e.g., the gastrointestinal and/or cardiovascular adverse effects of opioids [15] and NSAIDs [32]) and may ultimately affect the choice of pharmacotherapy. These concerns may be most important in patients experiencing greater pain (because they likely have the highest comorbidity burden and require a more intensive analgesic regimen) and in elderly patients (because they may be at higher risk for treatmentrelated toxicity than younger patients). 
OA negatively impacts HRQoL [33-38]. Because HRQoL is a multidimensional concept that spans several domains of patient health (i.e., physical functioning, psychologic functioning, social functioning, cognitive functioning, and general well-being), it may be a useful outcome for assessing treatment effects on patients [38]. In this study, HRQoL, as measured by the EQ-5D-5L VAS and utility index, was significantly lower among patients with moderate/severe pain with or without opioid use compared with those with no/mild pain without opioid use, and the differences in the EQ5D-5L utility index scores were clinically relevant, exceeding the estimated MID [26]. HRQoL was also lower among patients who used opioids versus those who did not. The impact on HRQoL observed here may have been related to both symptoms of OA and the untoward effects of treatment. Therefore, therapies that are both effective at controlling OA-related pain and have a low risk-benefit ratio may likely have the most benefit for HRQoL [38].

Previous studies have demonstrated an association between OA and reduced work productivity and daily activity [37, 39-41], and such impairments were also reported by patients in this study. These impairments, which were measured using the WPAI:SHP, were associated with higher pain level and the use of opioids. Work productivity and daily activity impairments were more than twofold higher in patients with moderate/severe pain with opioid use than in those with no/mild pain without opioid use. Impairment while working due to problem (i.e., presenteeism) was more prevalent than work time missed due to problem (i.e., absenteeism) and was thus the main driver of work impairment in this study. This finding is consistent with the results of other studies in OA showing that presenteeism exerted more of an impact on work productivity than absenteeism [37, 39, 41, 42]. In this study, notable differences were observed in work impairment between the US and EU cohorts, especially with regard to greater absenteeism in the EU, possibly reflecting cultural differences in the approach to health and disability in the workplace. Overall, these results underscore the pervasive impact of OA pain on patients' lives, with disease-related burdens placing limitations on recreational, social, and work activities.

This study also demonstrated discrepancies in opioid use for OA pain between the US and the five EU countries combined as well as between the individual EU countries. Opioids were used less frequently in the US than in the EU countries (23\% versus $33 \%$ of patients). Among the EU countries, opioids were used most frequently in Spain (46\%), followed by the UK (40\%), Italy (30\%), Germany (27\%), and France $(25 \%)$. Although it is not clear what factors contributed to these differences, they may have been related to regional variability in treatment practices, regulations for opioid prescriptions, and patient populations.

The major strength of this study is that participating patients reflected the consulting OA population from real-world clinical practice; however, there are limitations that should be considered. This study may have been affected by selection bias given that patients who consulted with their physician more frequently had a greater likelihood of being included in the DSP and information on patients not participating in the survey was not available. There is also an inherent limitation of unmeasured confounding by baseline demographic or disease characteristics because this is a real-world study, and no adjustments were made for potential confounders. In addition, given the cross-sectional nature of the study, relationships should be considered associative rather than causal. Furthermore, pairwise comparisons were not conducted between the patient groups, although current opioid use appeared to be associated with a higher burden relative to no opioid use at the same pain level. Recall and social desirability bias may have influenced the results of patient-reported outcomes, although for recall bias, the recall periods were generally short (WPAI had the longest recall at 7 days). Other limitations are the lack of information related to non-opioid analgesic use and equianalgesic opioid dosages (i.e., dosing of two opioids required to produce the same analgesic effect). Despite these potential limitations, these results are strengthened by the large sample size and the variety of outcomes assessed 
using validated measures (WOMAC, CCI, EQ5D-5L, and WPAI:SHP) [22-27].

\section{CONCLUSIONS}

In this multinational cross-sectional study, patients with moderate/severe OA pain and those currently using opioids reported significant burdens affecting multiple aspects of their lives. These results indicate that the impact of OA pain is multidimensional, is worsened by increasing pain intensity, and may not be adequately addressed by current treatment strategies.

\section{ACKNOWLEDGEMENTS}

The authors thank the study participants and physicians for their involvement in the study.

Funding. Sponsorship for this study and the journal's Rapid Service and Open Access Fees were funded by Regeneron Pharmaceuticals, Inc. (Tarrytown, NY, USA), and Teva Pharmaceutical Industries Ltd. (Frazer, PA, USA).

Medical Writing, Editorial, and Other Assistance. Medical writing and editorial support were provided by Mark Palangio and Jason Tuffree, respectively, at Ashfield Healthcare Communications (Lyndhurst, NJ, USA). Support for this assistance was provided by Teva Pharmaceutical Industries Ltd. and Regeneron Pharmaceuticals, Inc.

Authorship. All named authors meet the International Committee of Medical Journal Editors (ICMJE) criteria for authorship for this article, take responsibility for the integrity of the work as a whole, and have given their approval for this version to be published. All authors were involved in the study's conception and design, analysis and interpretation of the data, and drafting the article or revising it critically for important intellectual content. James Jackson and Jennifer Mellor were responsible for acquisition of the data.
Prior Presentation. These data were presented, in part, at the Osteoarthritis Research Society International (OARSI) 2019 World Congress; May 2-5, 2019; Toronto, Ontario, Canada; and the European Congress of Rheumatology (EULAR); June 12-15, 2019; Madrid, Spain.

Disclosures. James Jackson and Jennifer Mellor are employees of Adelphi Real World, which is a paid consultant to Teva Pharmaceutical Industries Ltd. and Regeneron Pharmaceuticals, Inc. Ravi Iyer is an employee of Teva Pharmaceutical Industries Ltd. with stock ownership. Wenhui Wei is an employee of Regeneron Pharmaceuticals, Inc.

Compliance with Ethics Guidelines. The current study used de-identified, aggregated patient data from the Adelphi Disease Specific Programme (DSP) ${ }^{\mathrm{TM}}$ and was granted exceptions from requiring ethics approval by the Western Institutional Review Board and the Freiburger Ethik Kommission International for the US and EU analysis, respectively.

Data Availability. The datasets generated and/or analyzed during the current study are not publicly available and are considered intellectual property of Adelphi Real World.

Open Access. This article is licensed under a Creative Commons Attribution-NonCommercial 4.0 International License, which permits any non-commercial use, sharing, adaptation, distribution and reproduction in any medium or format, as long as you give appropriate credit to the original author(s) and the source, provide a link to the Creative Commons licence, and indicate if changes were made. The images or other third party material in this article are included in the article's Creative Commons licence, unless indicated otherwise in a credit line to the material. If material is not included in the article's Creative Commons licence and your intended use is not permitted by statutory regulation or exceeds the permitted use, you will need to obtain permission directly from the copyright holder. To view 
a copy of this licence, visit http:// creativecommons.org/licenses/by-nc/4.0/.

\section{REFERENCES}

1. O'Neill TW, McCabe PS, McBeth J. Update on the epidemiology, risk factors and disease outcomes of osteoarthritis. Best Pract Res Clin Rheumatol. 2018;32(3):312-26.

2. Osteoarthritis Foundation International (OAFI). Osteoarthritis. 2019. https://oafifoundation.com/ en/what-is-osteoarthritis/. Accessed 6 Dec 2019.

3. Centers for Disease Control and Prevention. Osteoarthritis (OA). 10 Jan 2019. https://www.cdc. gov/arthritis/basics/osteoarthritis.htm. Accessed 6 Dec 2019.

4. Neogi T. The epidemiology and impact of pain in osteoarthritis. Osteoarthr Cartil. 2013;21(9):1145-53.

5. Hawker GA, Stewart L, French MR, et al. Understanding the pain experience in hip and knee osteoarthritis-an OARSI/OMERACT initiative. Osteoarthr Cartil. 2008;16(4):415-22.

6. Xie F, Kovic B, Jin X, He X, Wang M, Silvestre C. Economic and humanistic burden of osteoarthritis: a systematic review of large sample studies. Pharmacoeconomics. 2016;34(11):1087-100.

7. Schmidt TW. Approach to osteoarthritis management for the primary care provider. Prim Care. 2018;45(2):361-78.

8. Jordan KM, Arden NK, Doherty M, et al. EULAR Recommendations 2003: an evidence based approach to the management of knee osteoarthritis: Report of a Task Force of the Standing Committee for International Clinical Studies Including Therapeutic Trials (ESCISIT). Ann Rheum Dis. 2003;62(12):1145-55.

9. Zhang W, Doherty M, Arden N, et al. EULAR evidence based recommendations for the management of hip osteoarthritis: report of a task force of the EULAR Standing Committee for International Clinical Studies Including Therapeutics (ESCISIT). Ann Rheum Dis. 2005;64(5):669-81.

10. DeMik DE, Bedard NA, Dowdle SB, Burnett RA, McHugh MA, Callaghan JJ. Are we still prescribing opioids for osteoarthritis? J Arthroplasty. 2017;32(12):3578-82.e1.

11. da Costa BR, Nüesch E, Kasteler R, et al. Oral or transdermal opioids for osteoarthritis of the knee or hip. Cochrane Database Syst Rev. 2014;9: CD003115.

12. Smith SR, Deshpande BR, Collins JE, Katz JN, Losina E. Comparative pain reduction of oral non-steroidal anti-inflammatory drugs and opioids for knee osteoarthritis: systematic analytic review. Osteoarthr Cartil. 2016;24(6):962-72.

13. Krebs EE, Gravely A, Nugent S, et al. Effect of opioid vs nonopioid medications on pain-related function in patients with chronic back pain or hip or knee osteoarthritis pain: the SPACE randomized clinical trial. JAMA. 2018;319(9):872-82.

14. Welsch P, Petzke F, Klose P, Häuser W. Opioids for chronic osteoarthritis pain: an updated systematic review and meta-analysis of efficacy, tolerability and safety in randomized placebo-controlled studies of at least 4 weeks double-blind duration. Eur J Pain. 2020;24(4):685-703.

15. Ivers $\mathrm{N}$, Dhalla IA, Allan GM. Opioids for osteoarthritis pain: benefits and risks. Can Fam Phys. 2012;58(12):e708.

16. Vowles KE, McEntee ML, Julnes PS, Frohe T, Ney JP, van der Goes DN. Rates of opioid misuse, abuse, and addiction in chronic pain: a systematic review and data synthesis. Pain. 2015;156(4):569-76.

17. Deveza LA, Hunter DJ, Van Spil WE. Too much opioid, too much harm. Osteoarthr Cartil. 2018;26(3):293-5.

18. Bannuru RR, Osani MC, Vaysbrot EE, et al. OARSI guidelines for the non-surgical management of knee, hip, and polyarticular osteoarthritis. Osteoarthr Cartil. 2019;27(11):1578-89. https:// doi.org/10.1016/j.joca.2019.06.011.

19. Kolasinski SL, Neogi T, Hochberg MC, et al. 2019 American College of Rheumatology/Arthritis Foundation guideline for the management of osteoarthritis of the hand, hip, and knee. Arthritis Care Res (Hoboken). 2020;72(2):149-62.

20. Anderson P, Benford M, Harris N, Karavali M, Piercy J. Real-world physician and patient behaviour across countries: disease-specific programmes-a means to understand. Curr Med Res Opin. 2008;24(11):3063-72.

21. Eurostat. https://ec.europa.eu/eurostat/home. Accessed 1 Apr 2020.

22. Bellamy N, Buchanan WW, Goldsmith CH, Campbell J, Stitt LW. Validation study of WOMAC: a health status instrument for measuring clinically important patient relevant outcomes to antirheumatic drug therapy in patients with osteoarthritis of the hip or knee. J Rheumatol. 1988;15(12):1833-40. 
23. Bellamy N. WOMAC 3.1 Osteoarthritis Index User Guide XI. July 2016. https://www.womac.com/ womac/index.htm. Accessed 6 Dec 2019.

24. Charlson ME, Pompei P, Ales KL, MacKenzie CR. A new method of classifying prognostic comorbidity in longitudinal studies: development and validation. J Chronic Dis. 1987;40(5):373-83.

25. EuroQol Group. EQ-5D-5L. 2019. https://euroqol. org/eq-5d-instruments/eq-5d-5l-about/. Accessed 6 Dec 2019.

26. McClure NS, Sayah FA, Xie F, Luo N, Johnson JA. Instrument-defined estimates of the minimally important difference for EQ-5D-5L index scores. Value Health. 2017;20(4):644-50.

27. Reilly MC. Work Productivity and Activity Impairment Questionnaire: Specific Health Problem V2.0 (WPAI:SHP). August 2010. https://www. reillyassociates.net/WPAI_SHP.html. Accessed 6 Dec 2019.

28. Ayers DC, Franklin PD, Ploutz-Snyder R, Boisvert CB. Total knee replacement outcome and coexisting physical and emotional illness. Clin Orthop Relat Res. 2005;440:157-61.

29. Caporali R, Cimmino MA, Sarzi-Puttini P, et al. Comorbid conditions in the AMICA study patients: effects on the quality of life and drug prescriptions by general practitioners and specialists. Semin Arthritis Rheum. 2005;35(1 Suppl 1):31-7.

30. Kadam UT, Jordan K, Croft PR. Clinical comorbidity in patients with osteoarthritis: a case-control study of general practice consulters in England and Wales. Ann Rheum Dis. 2004;63(4):408-14.

31. van Dijk GM, Veenhof C, Schellevis F, et al. Comorbidity, limitations in activities and pain in patients with osteoarthritis of the hip or knee. BMC Musculoskelet Disord. 2008;9:95.

32. Harirforoosh S, Asghar W, Jamali F. Adverse effects of nonsteroidal antiinflammatory drugs: an update of gastrointestinal, cardiovascular and renal complications. J Pharm Pharm Sci. 2013;16(5):821-47.

33. Dominick KL, Ahern FM, Gold CH, Heller DA. Health-related quality of life and health service use among older adults with osteoarthritis. Arthritis Rheum. 2004;51(3):326-31.

34. Picavet HS, Hoeymans N. Health related quality of life in multiple musculoskeletal diseases: SF-36 and EQ-5D in the DMC3 study. Ann Rheum Dis. 2004;63(6):723-9.

35. Kawano MM, Araújo IL, Castro MC, Matos MA. Assessment of quality of life in patients with knee osteoarthritis. Acta Ortop Bras. 2015;23(6):307-10.

36. Hoogeboom TJ, den Broeder AA, de Bie RA, van den Ende $\mathrm{CH}$. Longitudinal impact of joint pain comorbidity on quality of life and activity levels in knee osteoarthritis: data from the Osteoarthritis Initiative. Rheumatology (Oxford). 2013;52(3): 543-6.

37. Nakata K, Tsuji T, Vietri J, Jaffe DH. Work impairment, osteoarthritis, and health-related quality of life among employees in Japan. Health Qual Life Outcomes. 2018;16(1):64.

38. Farr Ii J, Miller LE, Block JE. Quality of life in patients with knee osteoarthritis: a commentary on nonsurgical and surgical treatments. Open Orthop J. 2013;7:619-23.

39. Dibonaventura Md, Gupta S, McDonald M, Sadosky A. Evaluating the health and economic impact of osteoarthritis pain in the workforce: results from the National Health and Wellness Survey. BMC Musculoskelet Disord. 2011;12:83.

40. Hubertsson J, Petersson IF, Thorstensson CA, Englund M. Risk of sick leave and disability pension in working-age women and men with knee osteoarthritis. Ann Rheum Dis. 2013;72(3):401-5.

41. Kingsbury SR, Gross HJ, Isherwood G, Conaghan PG. Osteoarthritis in Europe: impact on health status, work productivity and use of pharmacotherapies in five European countries. Rheumatology (Oxford). 2014;53(5):937-47.

42. Dibonaventura Md, Gupta S, McDonald M, Sadosky A, Pettitt D, Silverman S. Impact of self-rated osteoarthritis severity in an employed population: cross-sectional analysis of data from the national health and wellness survey. Health Qual Life Outcomes. 2012;10:30. 